\title{
Vicente Cervera Salinas: Borges en la Ciudad de los Inmortales. Sevilla: Editorial Renacimiento, 2014.
}

A la hora de abrir la nueva monografía de Vicente Cervera Salinas sobre Jorge Luis Borges, planteé la cuestión de qué más se puede decir sobre la obra del escritor argentino. Al terminar la lectura del libro, comprendí que mi planteamiento inicial era meramente superficial y que, en vez de concentrarse en el qué, se debe desarrollar el cómo: ¿cómo escribir sobre Borges? Cervera no pretende englobar y machacar la bibliografía inabarcable que se ha escrito sobre el autor, sino parte de un acercamiento subjetivo, determinado por su propio entusiasmo por «El inmortal», pero sin prescindir en sus textos del valor crítico y de la objetividad. Borges en la Ciudad de los Inmortales es una recopilación de sus artículos que versan sobre la narrativa, poesía y ensayística, en suma, la filosofía y estética borgeanas, en los que se hace mención de los motivos arquetípicos del autor. Entre éstos, la interpretación de la inmortalidad a la que alude el título es presentada desde el punto de vista de la anamnesis platónica. En varios ensayos se acerca a la inmortalidad desde el procedimiento típicamente borgeano del tratamiento del tiempo, concretamente, las diferentes aproximaciones a lo eterno, para "mostrarnos esa «modernizada» concepción de la inmortalidad como reminiscencia literaria" (346), tal como lo hace Borges en el cuento mencionado.

Los artículos donde Vicente Cervera alcanza mayor profundidad filológica son los que tratan la poesía borgeana, hecho nada sorprendente puesto que el catedrático y poeta español escribió su tesis doctoral sobre dicho tema, con el título de La poesía de Jorge Luis Borges: historia de una eternidad (Murcia: Editum, 1992). Se nos ofrece una interesente lectura paralela entre los diferentes desdoblamientos del sujeto, desde la naturaleza humana y al mismo tiempo divina del Cristo en «Juan I, 14», a través de la figura del bifronte Jano en varios poemas borgeanos, hasta llegar a la pluralidad whitmaniana de la voz poética y sus recreaciones por el escritor argentino. Cervera también ahonda en la duplicación de las perspectivas del tiempo y espacio, en la especificación de la figuración de antítesis entre pasado y futuro, entre Occidente y Oriente. La lectura de Cervera, por lo tanto, es intertextual, pero sin entrar innecesariamente en las teorías al respecto.

La figura de Jano igualmente aparece en los ensayos borgeanos, según Cervera, para señalar la "unidad bifurcada", las direcciones opuestas de la ficción y del raciocinio, la subjetividad y objetividad paralelas dentro del propio texto. El crítico español ofrece una interpretación metafísica de los ensayos de Borges que denomina «existencialismo textual», y que al mismo tiempo contiene las claves interpretativas para los cuentos y poemas del argentino. Cervera también le atribuye dos innovaciones del género: por una parte, la introducción de una nueva estética del ensayo, la de la abstracción - el laberinto como metáfora del modo de pensamiento borgeano, es decir, la preeminencia de la búsqueda al encuentro de la salida $-\mathrm{y}$, por otra parte, la visión poética del ensayo como realidad literaria.

Los otros artículos de Cervera atañen a los precedentes que habían contribuido a la formación del mismo pensamiento borgeano. El tema de lo eterno aparece en el análisis del ensayo de Borges sobre los traductores de las Mil y una noches y la figura sacralizada del argentino Domingo Faustino Sarmiento, "un personaje histórico cuya obra - y cuya figura también - trasciende las limitaciones de la cronología y de sus barreras conceptuales" (184). Cervera profundiza de manera detenida en las relaciones de las reflexiones de Pedro Henríquez Ureña, Alfonso Reyes y Jorge Luis Borges, a quienes denomina los tres humanistas del siglo pasado, tres artistas del pensamiento y la palabra. También menciona a Jorge Santayana - cuya recepción empezó por la mediación del dominicano mencionado - señalando una atracción común, otra vez, por el concepto de la eternidad. Cervera cierra su monografía con un texto que 
contempla el pensamiento borgeano desde una perspectiva más alejada, la del número conmemorativo de los treinta años de existencia de la revista.

El catedrático español enmarca su libro con un prólogo y epílogo conexos que contienen su interpretación sobre su cuento predilecto, una imitación lúdica del recurso estructural del relato marco utilizado por Borges en «El inmortal», en el que otra vez aparecen los temas eternos del argentino. Aunque el foco principal de su monografía no es un acercamiento propiamente dicho a los relatos borgeanos, el análisis que ofrece sobre el primer cuento de $E l$ Aleph (1949) arroja luz sobre los tópicos literarios predilectos del argentino: la pluralidad de las referencias, el motivo de lo infinito, el conocimiento y la relectura como rememoración, la tensión entre lo verdadero y lo falso, la poética espacial del texto, o las tres pilares del universo filosófico de Borges (la judía, la griega y la anglosajona). Todos estos tópicos revelan la condensación borgeana de evocar una red de asociaciones con el procedimiento tan simple y al mismo tiempo tan complicado del palimpsesto.

Según el análisis de Cervera, la condensación de los niveles compositivos de «El inmortal» se complementa con el uso de diferentes tipos de narradores y con tres perspectivas de una raíz común: la constancia de lo repetido. El crítico establece un paralelismo acertado entre la inconcebilidad del espacio de la Ciudad de los Inmortales y la del tiempo del Aleph, siendo ambos "la suma literaria del saber" (41). En dicho plano espaciotemporal, el único ser inmortal es el escritor, pero todos los escritores son el mismo ser: aquí reside la clave de la bella paradoja borgeana de la inmortalidad, que se nos muestra - según las acertaciones de Cervera - desde una perspectiva desmitificadora y deconstructiva, como falacia y engaño, en resumidas cuentas, desde la ironía tan típica del argentino.

El libro de Vicente Cervera Salinas, por lo tanto, no es un primer acercamiento a la obra borgeana, ni es una lectura introductoria para los lectores principiantes de su obra, sino una monografía bien pensada, abundante y con gran capacidad de síntesis. Es un bello ejemplo de cómo escribir sobre Borges: disminuyendo las muchas veces innecesarios términos de la crítica literaria y limitarse a las palabras clave de la eternidad y la inmortalidad, profundidad infinita de la metafísica borgeana, cuyas representaciones contornea Cervera en los diferentes géneros cultivados por el argentino, quizá llegando a las mismas conclusiones, pero siempre sabiendo que éstas, como la figura de Borges, son eternas.

(C) Petra Báder
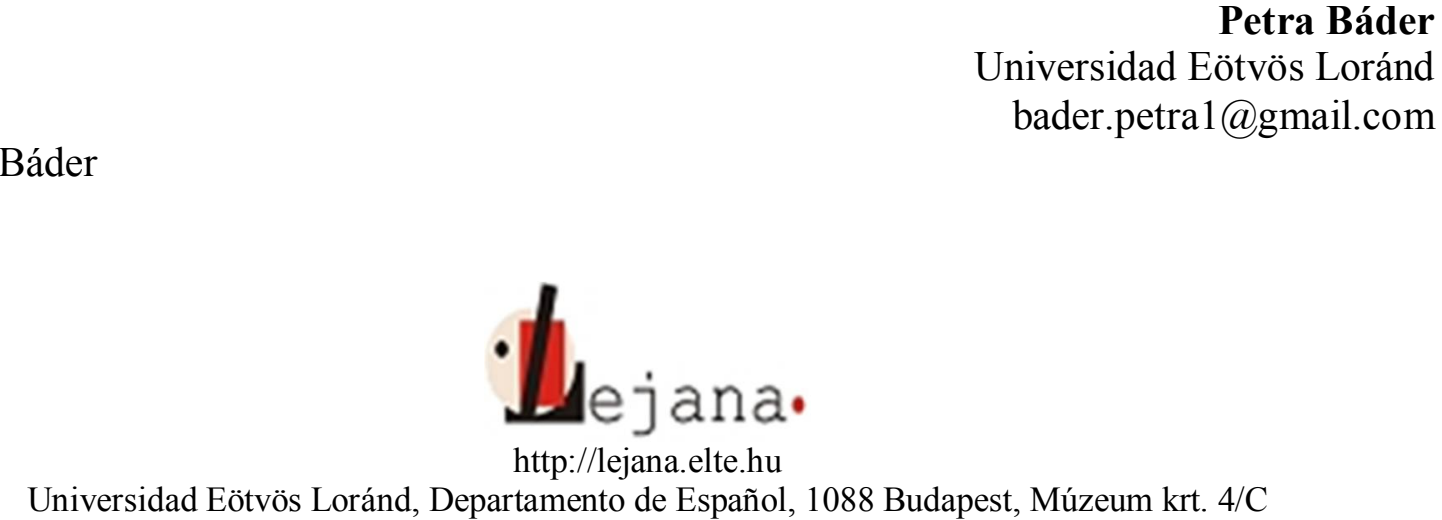

Recibido: 06 de agosto de 2015

Aceptado: 13 de octubre de 2015 